DOI: $10.34185 / 1991-7848.2020 .01 .06$

УДК 669.15-198

Ю.Г. Качан, В.Ю. Міщенко

\title{
ВИЗНАЧЕННЯ ОБСЯГІВ РОЗПЛАВУ ТА ШЛАКУ ПІД ЧАС ПЛАВКИ В ФЕРОСПЛАВНІЙ ПЕЧІ
}

В даній статті представлена модель міжфазового переходу шихтових матеріалів, що відбувається внаслідок їх нагрівання з метою визначення кількості одержаних рідких феросплавів та шлаку в динаміці процесу. Запропонована методика та математичні залежності для розрахунку кількості розплаву, що накопичується у подині ванни руднотермічної печі. За таким показником дає можливість в подальшому управляти технологічним процесом зливу готової продукції за цим показником.

Ключові слова: руднотермічна піч, феросплави, шихта, розплав, температура розплавлення, елементарний об'єм.

\section{Вступ}

В структурі гірничо-металургійного комплексу України важливе значення має виробництво феросплавів, яке представлене Запорізьким (ЗФЗ), Стаханівським (СФЗ) i Нікопольським (НЗФ) феросплавними заводами. Електропічні потужності на них складають 1500 МВ·А. Основними видами феросплавів, які виробляються на зазначених вище підприємствах, $є$ феросиліцій 3 вмістом кремнію від 20\% до 90\% (ДСТУ 1415-78), феросилікомарганець - від 15 до 20\% Si (ДСТу 3548-97) та феромарганець (ДСТУ 3547-97) [1-3].

Зміцнення позицій вітчизняних феросплавів в умовах жорстокої конкуренції на європейському, американському та азіатському ринках цієї продукції може бути досягнуто шляхом підвищення якості сплаву за рахунок зменшення вмісту домішкових елементів, регламентованим фракційним складом та зниженням собівартості внаслідок зменшення питомої витрати електроенергії.

\section{Аналіз досягнень та постановка задачі}

Проблемні питання теорії i технології одержання феросплавів, вдосконалення конструкцій руднотермічних електропечей, оптимізація електричних режимів плавки постійно обговорюються на відповідних міжнародних конгресах. В працях [4-5] розглядається можливість комплексного підходу щодо моделювання роботи печі, представлений алгоритм та відповідні формули для розрахунку теплових процесів

(C) Качан Ю.Г., Мищенко В.Ю., 2020 
перетворення шихтових матеріалів в розплав. Однак для більш точного відображення реальних фізичних процесів, що відбуваються в робочому просторі ванни, необхідно врахувати ще й той факт, що при нагріванні шихти змінюється її щільність. Тобто відбувається перехід з твердої фази в рідку, а це в свою чергу призводить до просідання матеріалів в РТП. Отже, метою даної роботи $\epsilon$ моделювання зазначеного процесу переходу 3 подальшою можливістю більш точного визначення деяких параметрів шихти у динаміці.

\section{Викладення матеріалу}

Ванна РТП є складною за своїм устроєм. Вона містить шихту, що знаходиться у різному фізико-хімічному стані (від твердих шматків до тістоподібної магми), шлак i метал. Фізичні процеси, що при цьому відбуваються є дуже різними. Одні з них є безперервними, а інші, такими, що здійснюються до повного проплавлення одноразово завантажених матеріалів.

На більшості підприємств України процес виплавки феросплавів $\epsilon$ безперервним, тобто випуск готової продукції відбувається циклічно 3 зупиненням РТП тільки у разі аварійних або технологічних ремонтів. При цьому виплавку здійснюють за допомогою технологічних карт, де завантаження шихти, тривалість виплавки, момент випуску рідкого металу та ін., обумовлюють показаннями електричних лічильників i нормами споживання електричної енергії на тонну готової продукції.

Нагрівання матеріалів в об’ємі ванни є неоднорідним, але металурги виділяють температурні зони, які подано на рис. 1 [6]. Так у нижній частині ванни РТП присутній рідкий розплав, що називається демпферним прошароком, який необхідний для захисту внутрішньої оболонки ванни від температурних перегрівань. Над ним 3 температурою плавлення (на жаль, навіть більшою) знаходиться рідкий метал (кінцевий продукт). На цьому ж рівні $є$ вікно через яке відбувається зливання останнього та шлаку. В процесі нагрівання шихти до температури плавлення відбувається утворення рідкого металу та шлаку, останній піднімається над першим. В так званій шлаковій зоні знаходяться електроди, глибину занурення яких можна змінювати.

У верхній частині ванни РТП виділяють дві зони: холодну (3 температурою шихти $300 . .700{ }^{\circ} \mathrm{C}$ ) та розігріту (вище $700{ }^{\circ} \mathrm{C}$ ), що вже має червоний колір. Оскільки процес виплавки феросплавів $є$ безперервним, то зливання рідкого металу й шлаку, засипання нових шихтових матеріалів відбувається циклічно впродовж певного часу. По завершенні плавки одержують готову продукцію, яку випускають з робочого об’єму ванни, проте зазначені температурні зони зберігаються і мають постійних характер. 


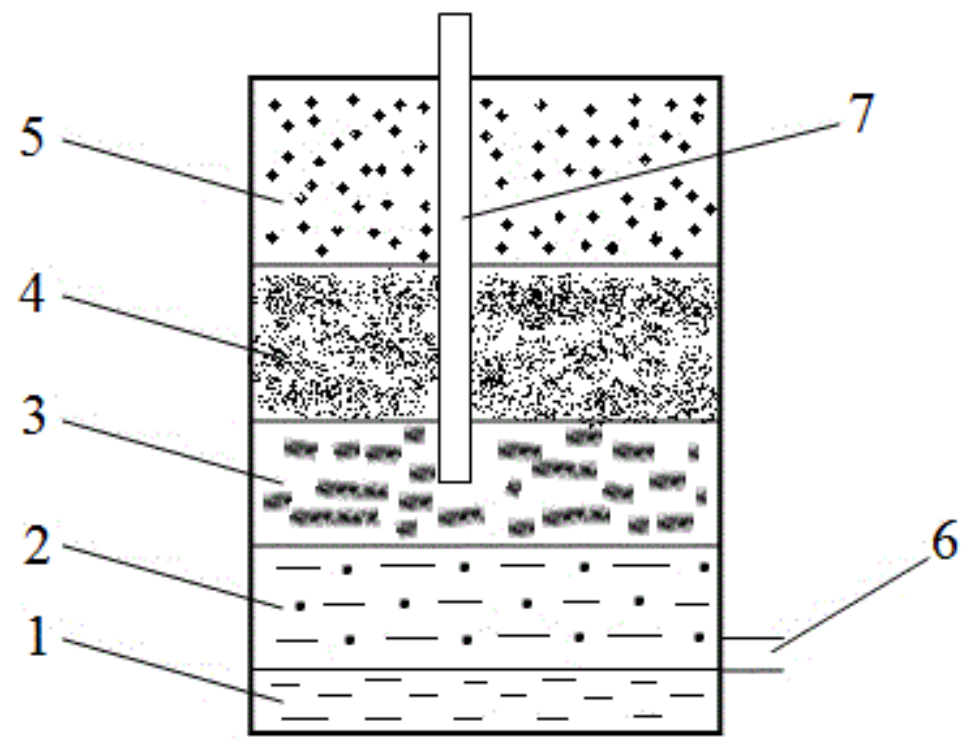

1 - рідкий розплав (демпферний шар); 2 - рідкий розплавлений метал; 3 - шлакова зона; 4 - шихта, що розігріта до червоного кольору; 5 - зона холодної шихти; 6 - вікно для зливу рідкого феросплаву та шлаку; 7 - електрод.

Рисунок 1 - Температурні зони в ванні руднотермічної печі під час виплавки феросплавів

Якщо розглядати дію руднотермічної печі від початку іï роботи, то у загальному вигляді можна виділити певні етапи. На першому 3 них розігрівається робочий об’єм. Щоб уникнути зайвих втрат електроенергії в шихту додають значну кількість коксику, оскільки він має найбільшу серед складових електричну провідність, це призводить до більш рівномірного початкового розігрівання. Внизу ванни поступово утворюється певний шар рідкого металу. Далі підсипають всі інші необхідні компоненти для виплавляння необхідної марки феросплавів, після цього починають утворюватися теплові зони, що зазначені на рис. 1, і відбувається процес плавки, який і регламентується технологічними картами. 3 рештою рідкий метал разом зі шлаком зливається. Залишковий матеріал остається у печі, що зі своєю певною температурою опускається до низу ванни на об'єм, який звільнився у ній. Після чого шихту знову підсипають і нагрівання матеріалів до рідкого стану повторюють, а процес одержання феросплавів набуває циклічного характеру.

Щоб змоделювати процес утворення розплаву у ванні руднотермічної печі запропоновано розбити іiі внутрішній простір на елементарні об’єми. Для цього існує багато способів, але нами обраний та дещо змінений метод, що базується на системі циліндричних координат [7], відповідно яким ванна розглядається як циліндр з висотою $H_{c}$ та радіусом $R$. Розіб'ємо його на ряд елементарних об’ємів у вигляді сектора зі сторонами $\Delta R, \Delta z$ та кутом $\Delta \varphi$, як 
представлено на рис. 2. Подальші розрахункові точки розташуємо в геометричних центрах останніх.

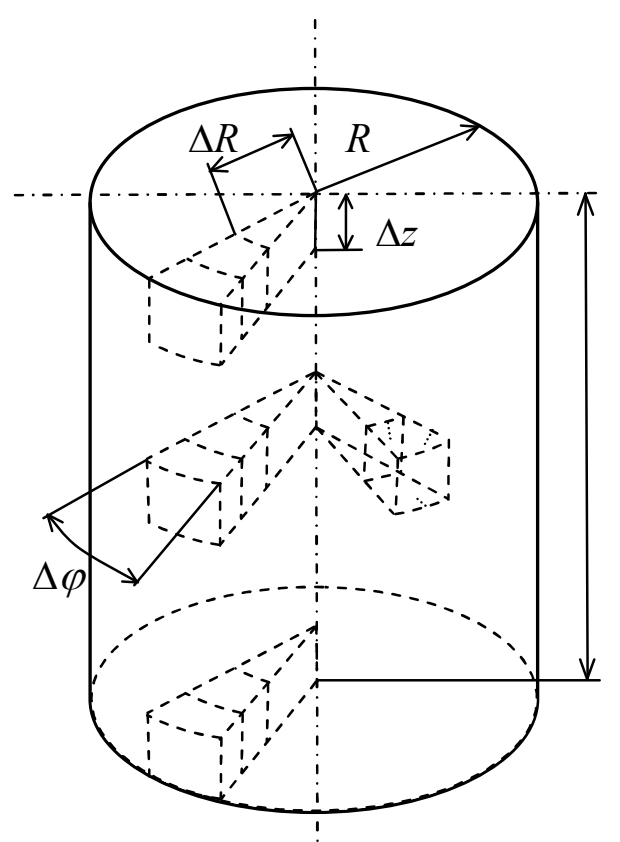

Рисунок 2 - Представлення ванни руднотермічної печі у вигляді елементарних об’ємів

Зазначені параметри $\Delta z$ та $\Delta \varphi$ розраховуються наступним чином:

$$
\begin{gathered}
\Delta \phi=\frac{360}{N_{\phi}} . \\
\Delta z=\frac{H_{c}}{N_{z}} .
\end{gathered}
$$

Прийнявши незмінним значення $\Delta V$ для кожного елементарного об'єму визначимо інтервали $\Delta R_{k}$ за віссю $R$ :

$$
\Delta R_{k}=\sqrt{\frac{\Delta V \cdot N_{\phi}}{\pi \cdot \Delta z}} \cdot(\sqrt{k+1}-\sqrt{k}) .
$$

Після встановлення всіх необхідних параметрів щодо розбиття, стає можливим представити ванну РТП як сукупність однооб'ємних складових. Завдяки значенням $\Delta V, N_{\varphi}$ та $N_{z}$, які довільно задаються, можна змінювати загальну кількість елементарних об'ємів, забезпечуючи цим необхідну похибку моделювання. У результаті зазначених дій, стає можливим описати процес утворення розплаву та шлаку і їх переміщення до низу ванни у зону рідкого шару, з якого потім і відбувається злив. Міжфазове перетворення матеріалу 3 твердої фази у рідку визначається значенням температури, за якої відбувається 
розплавлення різних видів феросплавів. На рис. 3 представлений алгоритм для визначення кількості утвореного розплаву та шлаку в дискретні проміжки часу.

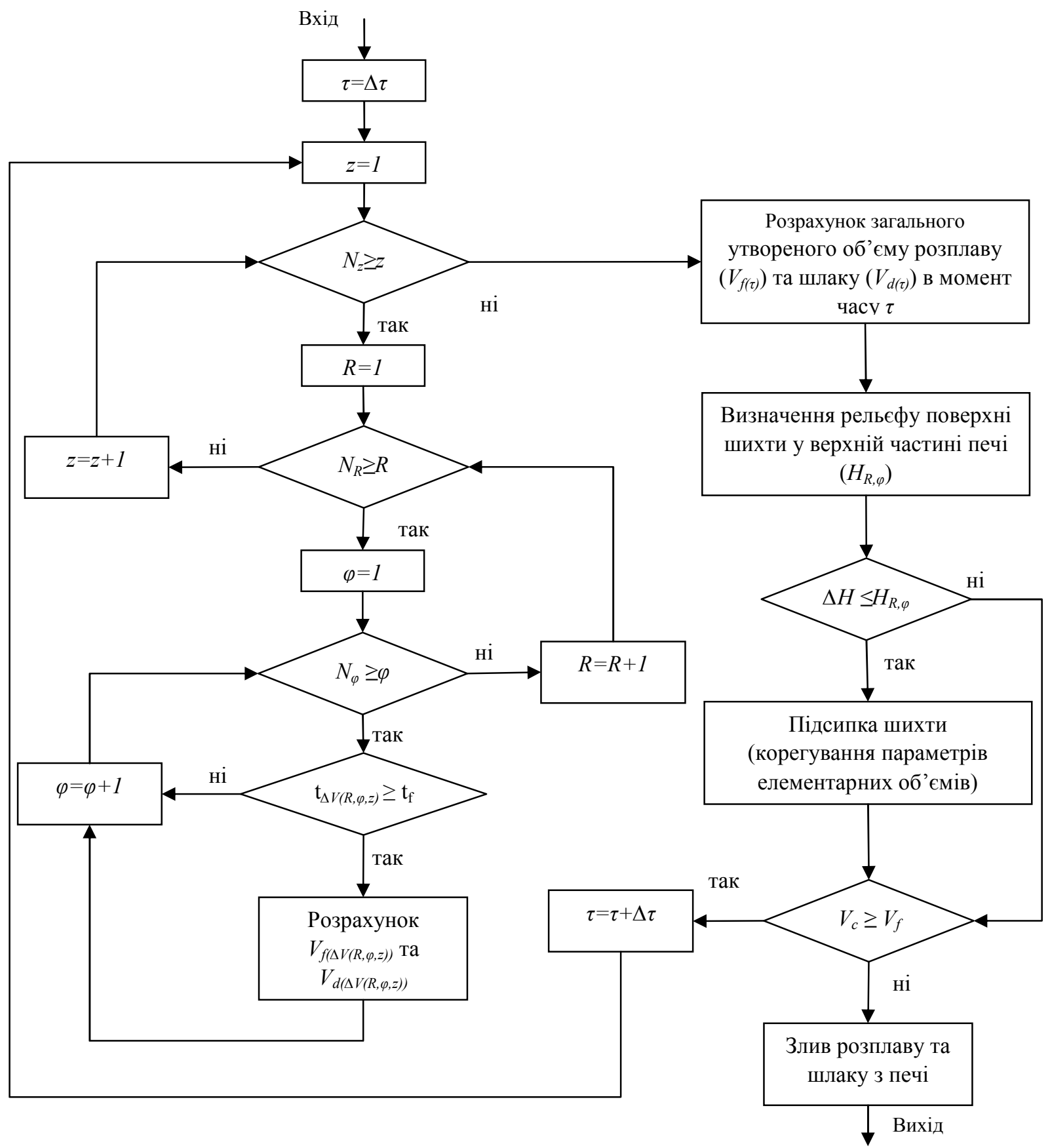

Рисунок 3 - Алгоритм для визначення кількості утвореного розплаву та шлаку в динаміці

Нами використані наступні позначення: $\tau$ - час; $\Delta \tau$ - проміжок часу; $R, \varphi, z$ - координати центру елементарного об'єму за трьома осями; $N_{\varphi}$ - кількість сегментів $\Delta \varphi$ розбиття циліндра за кутом $\varphi ; N_{z}-$ кількість проміжків $\Delta z$ розбиття циліндра за висотою заповнення ванни шихтою; 
$N_{R}$ - кількість сегментів за радіусами розбиття печі; $\Delta V$ - об'єм елементарного сектору; $t_{\Delta V(R, \varphi, z)}$ - температура елементарного об'єму 3 відповідними

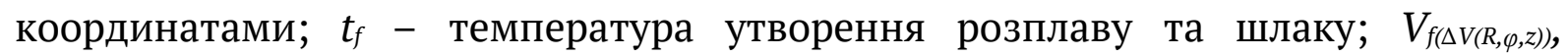
$V_{d(\Delta V(R, \varphi, z))}$ - об'єм утвореного розплаву та шлаку в елементарному об'ємі 3 координатами $R, \varphi, z ; V_{f(\tau)}$ та $V_{d(\tau)}$ - загальний об'єм утвореного розплаву та шлаку в момент часу $\tau$ відповідно; $\left(H_{R, \varphi}\right)$ - рівень просідання шихти від початкового його заповнення; $\Delta H$ - гранично допустимий рівень просідання шихти; $V_{c}$ та $V_{f}$ - заданий та розрахунковий загальний об'єм розплаву, що утворився 3 початку роботи печі.

Вхідними даними для розрахунків за цим алгоритмом $є$ значення температури в кожному елементарному об'ємі, після чого на будь-якому етапі часу за допомогою відповідних циклів відбувається перевірка кожного елементарного об'єму на досягнення в ньому температури розплавлення. Якщо це відбувається то, знаючи масу та густину рідкого розплаву та шлаку при даній температурі, розрахуємо їх реальний об'єм, одержаний в результаті зазначених фазових переходів, в одному елементарному об’ємі:

$$
\begin{aligned}
& V_{f(\Delta V(R, \phi, z))}=\frac{m_{c} \cdot \alpha_{f}}{\rho_{f}} ; \\
& V_{d(\Delta V(R, \phi, z))}=\frac{m_{c} \cdot \alpha_{d}}{\rho_{d}},
\end{aligned}
$$

де $V_{f(\Delta)}, V_{d(\Delta)}-$ об'єм рідкого феросплаву та шлаку в елементарному об'ємі (м³); $m_{c}$ - маса шихтових матеріалів, що знаходиться в елементарному об'ємі (кг);

$\rho_{f}-$ густина рідкого розплаву $\rho_{f}=7140\left(\mathrm{k} / \mathrm{M}^{3}\right)$;

$\rho_{d}-$ густина шлаку $\rho_{d}=2800\left(\mathrm{kг} / \mathrm{M}^{3}\right)$;

$\alpha_{f}-$ коефіцієнт отримання чистих феросплавів з шихтових матеріалів $\alpha_{f}=0,7$

$\alpha_{d}-$ коефіцієнт отримання шлаку з шихтових матеріалів $\alpha_{d}=0,3$ [8].

Після цього розраховується загальний утворений об'єм розплаву та шихти за даний проміжок часу:

$$
\begin{aligned}
& V_{f(\tau i)}=\sum V_{f(\Delta V(R, \phi, z))} ; \\
& V_{d(\tau i)}=\sum V_{d(\Delta V(R, \phi, z))} .
\end{aligned}
$$

При фазовому переході шихта перетворюється в розплав та шлак внаслідок чого в відповідних місцях ванни руднотермічної печі відбувається іiі осідання до низу. Припустимо, що в елементарних об'ємах $A, B, C, D, E, F$ це сталося і розплав та шлак, який просочився по вертикалі (рисунок 4a), 
вивільнив простір, куди переміщається верхній об'єм, а зона розплаву при цьому збільшується на таку ж величину (рисунок 4б).

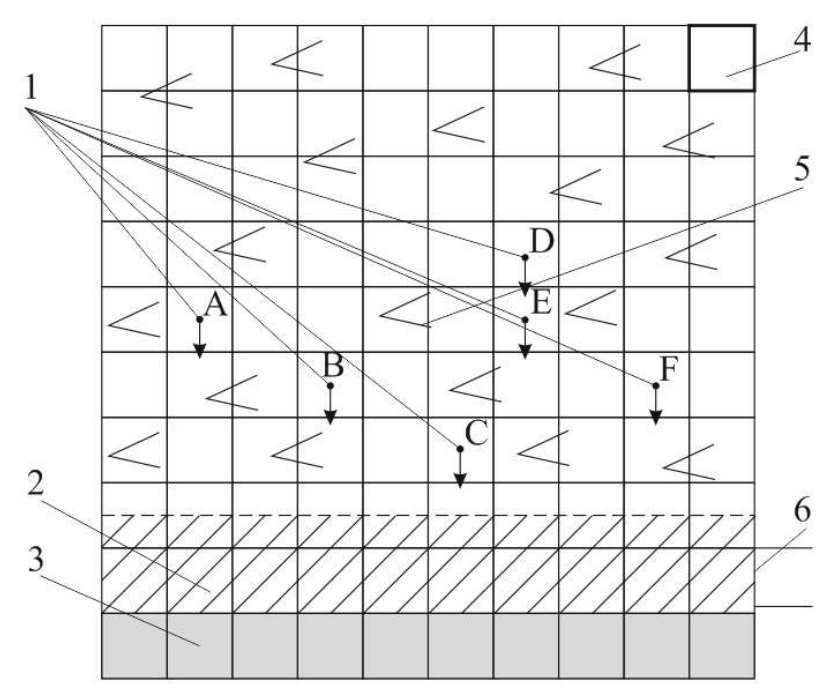

a)

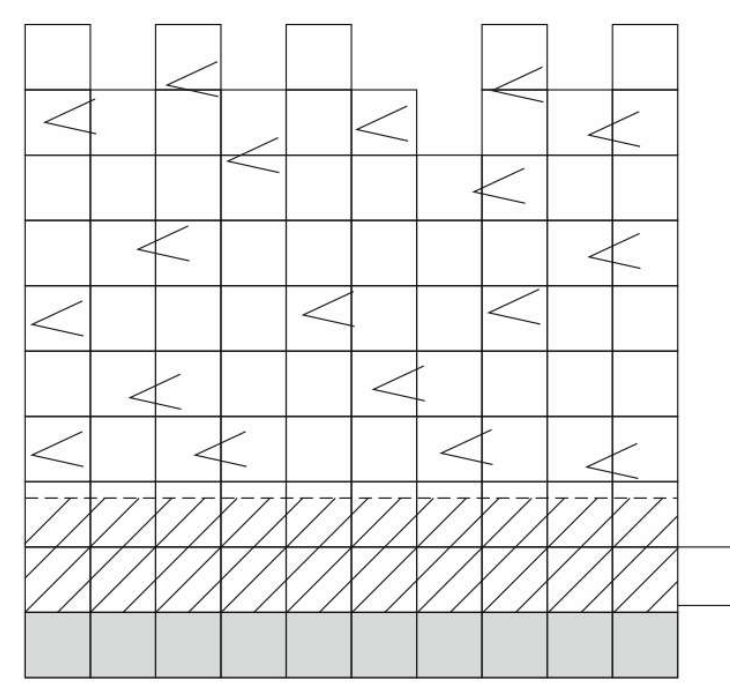

б)

1 - елементарні об’єми, температура яких досягла величини за якої відбувається фазовий перехід ; 2 - рідкий розплав; 3 - демпферний шар розплаву;

4 - елементарний об'єм; 5 - шихтові матеріали;

6 - вікно для зливу рідкого феросплаву та шлаку.

Рисунок 4 - Просідання шихти внаслідок утворення розплаву та шлаку

3 рисунку 46 видно, що в результаті фазових перетворень шихтових матеріалів в різних об’ємних точках робочого простору РТП збільшується кількість готового рідкого феросплаву та відбувається просідання шихти у верхній частині ванни. Максимально допустима величина просідання шихти поблизу електродів строго регламентується технічною документацією печі, тому якщо розрахункова величина $H_{R, \varphi}$ досягла її значення необхідно робити підсипку шихти під електроди. Внаслідок чого в алгоритм вносяться корективи щодо стану поверхні рельєфу та параметрів верхніх елементарних об'ємів.

Наступним кроком в алгоритмі $€$ порівняння розрахункового об'єму утвореного розплаву за здійснений проміжок плавки 3 його заданим значенням. Якщо ці показники вже співпадають то треба зливати розплав та шлак, в іншому випадку переходимо до наступного проміжку часу і виконуємо ці розрахунки доки зазначена умова не виконається.

Тож, сумуючи всі елементарні об’єми, що досягли температури розплаву, можна визначити реальну кількість рідкого феросплаву, що утворюється в печі. Завдяки цьому стає можливим проводити злив готової продукції та шлаку 3 ванни РТП не за встановленими показниками спожитої електроенергії, а коли кількість розплаву досягне необхідної величини. Тобто, знаючи розподіл температури у ванні печі в певні проміжки часу [5], стає можливим 
розрахувати об’єм рідкого феросплаву, що утворився, і визначати кількість наявної готової продукції в будь-який момент плавки. Також завдяки представленій методиці можна відслідковувати в якій саме частині ванни РТП відбувається просідання шихти. А так як технологічний процес отримання феросплавів в більшості випадків є безперервним, то це дає змогу визначити де і в якій кількості необхідно її підсипати.

\section{Висновки}

При комплексному підході щодо процесу моделювання роботи РТП, однією із задач є визначення кількості розплавленого металу, що знаходиться в подині ванни. Це питання і вирішується завдяки представленим методиці та алгоритму, які дають можливість дізнатися скільки є розплаву в той чи інший момент часу роботи печі. Завдяки цьому стає можливим контролювати технологічний процес отримання феросплавів не за показником спожитої електричної енергії (як це робиться зараз), а за необхідною чи регламентованою кількістю наявного розплаву. Це, в свою чергу, призведе до економії спожитої електроенергії і зменшить частку в собівартість продукції, що відповідає витратам на забезпечення плавки енергією.

\section{ЛІТЕРАТУРА}

1. Никопольские ферросплавы / М. И. Гасик [и др.]. Днепропетровск : Системные технологии, 2004. $272 \mathrm{c}$.

2. Гаврилов В. А., Гасик М. И. Силикотермия марганца. Днепропетровск : Системные технологии, 2001. $512 \mathrm{c.}$

3. Гасик М. И., Лякишев Н. П. . Физикохимия и технология электро-ферросплавов : учеб. для вузов. Днепропетровск : Системные технологии, 2005. 448 с.

4. Качан Ю.Г., Міщенко В.Ю. Щодо комплексного підходу при моделюванні роботи руднотермічної печі [Текст] // Металургія : наукові праці Запорізької державної інженерної академії. - Запоріжжя : РВВ ЗДІА, 2018. - Вип. 1 (39). - С. 126-130.

5. Качан Ю.Г., Ліуш Ю.Б., Міщенко В.Ю. Алгоритм розрахунку температурного поля ванни руднотермічної печі // Вісник ХНУ. - 2018. - № 3 (261). - С. 19-22.

6. Нехамин С. М. Управление энергетической структурой рабочего пространства дуговых сталеплавильных и руднотермических печей- механизм повышения эффективности их работы / С. М. Нехамин // Электрометаллургия.- 2013. - № 11.- С. 9-16.

7. Качан Ю.Г., Баташова Н.А. Динамическая модель температурного поля в электрическом теплоаккумулирующем преобразователе // Теория и практика металлургии. Днепропетровск. - 2007. - №6 (61). - С. 63-66.

8. Мысик В.Ф. Металлургия ферросплавов: технологические расчеты : учебное пособие /В. Ф. Мысик, А. В. Жданов, В. А. Павлов. - Екатеринбург : Изд-во Урал. ун-та, 2018. - 536 с.

\section{REFERENCES}

1. Nikopolskie ferrosplavyi / M. I. Gasik [i dr.]. Dnepropetrovsk : Sistemnyie tehnologii, 2004. 272 s.

2. Gavrilov V. A., Gasik M. I. Silikotermiya margantsa. Dnepropetrovsk : Sistemnyie tehnologii, 2001. $512 \mathrm{~s}$.

3. Gasik M. I., Lyakishev N. P. . Fizikohimiya i tehnologiya elektro-ferrosplavov : ucheb. dlya vuzov. Dnepropetrovsk : Sistemnyie tehnologii, 2005. 448 s. 
4. Kachan Yu.H., Mishchenko V.Iu. Shchodo kompleksnoho pidkhodu pry modeliuvanni roboty rudnotermichnoi pechi [Tekst] // Metalurhiia : naukovi pratsi Zaporizkoi derzhavnoi inzhenernoi akademii. - Zaporizhzhia : RVV ZDIA, 2018. - Vyp. 1 (39). - S. 126-130.

5. Kachan Yu.H., Liush Yu.B., Mishchenko V.Iu. Alhorytm rozrakhunku temperaturnoho polia vanny rudnotermichnoi pechi // Visnyk KhNU. - 2018. - № 3 (261). - S. 19-22.

6. Nehamin S. M. Upravlenie energeticheskoy strukturoy rabochego prostranstva dugovyih staleplavilnyih i rudnotermicheskih pechey- mehanizm povyisheniya effektivnosti ih rabotyi / S. M. Nehamin // Elektrometallurgiya.- 2013. - \# 11.- S. 9-16.

7. Kachan Yu.G., Batashova N.A. Dinamicheskaya model temperaturnogo polya v elektricheskom teploakkumuliruyuschem preobrazovatele // Teoriya i praktika metallurgii. Dnepropetrovsk. 2007. - \#6 (61). - S. 63-66.

8. Myisik V.F. Metallurgiya ferrosplavov: tehnologicheskie raschetyi : uchebnoe posobie /V. F. Myisik, A. V. Zhdanov, V. A. Pavlov. - Ekaterinburg : Izd-vo Ural. un-ta, 2018. - 536 s.

Received 06.01.2020.

Accepted 15.01.2020.

UDC 669.15-198

Y.Kachan, V. Mishchenko

\section{DETERMINATION OF VOLUMES OF MELT AND SLAG DURING MELTING IN THE ORE-THERMAL FURNACE}

Analysis of recent research and publications. Problematic issues of theory and technology of production of ferroalloys, improvement of structures of ore-thermal electric furnaces, optimization of electric modes of melting are constantly discussed at the relevant international congresses. For a more accurate reflection of the actual physical processes occurring in the working space of the bath, it is necessary to take into account that when the mixture is heated its density changes and occurs between the phase transition.

The aim of the study. The purpose of this work is to simulate the process of transition of the charge in the melt, with the subsequent possibility of more accurate determination of some its parameters in the dynamics.

Presentation of the main research material. Bath OTF is complex in its structure. It contains a mixture of various physical and chemical conditions (from solid pieces to doughy magma), slag and metal. The physical processes that take place are very different. Some of them are continuous, and others, which are carried out before full melting of single-loaded materials.

In order to simulate the process of formation of a melt in a bath of an ore-thermal furnace it is proposed to break its inner space into elementary volumes. We have chosen and slightly modified the method based on the system of cylindrical coordinates, according to which the furnace bath is regarded as a cylinder. We will place further calculation points in the geometric centers of these volumes.

The transition of the charge from the solid to the liquid phase is determined by the temperature at which the melting of different types of ferroalloys occurs. If this is the case, knowing the mass and density of the liquid melt and slag at a given temperature, we calculate their real volume, obtained as a result of these phase transitions, in one elementary volume. Thereafter, the total melt volume and charge formed over a given period of time is calculated. 
During the phase transition, the charge is converted into a melt and slag resulting in its settling down to the bottom of the ore-thermal furnace bath. The maximum permissible amount of charge settling near the electrodes is strictly regulated by the technical documentation of the furnace, so if the calculated value has reached this value, the charge of the charge under the electrodes should be made.

It is also possible to compare the calculated volume of the formed melt over the melting interval with its predetermined value. If these indicators are already the same, then it is necessary to merge the melt and slag, otherwise we go to the next period of time and perform these calculations until the specified condition is fulfilled.

Conclusions. With a comprehensive approach to the process of modeling the operation of OTF, one of the tasks is to determine the amount of molten metal in the bottom of the bath. This question is solved by the presented methodology and algorithm, which give an opportunity to find out how much melt there is at one or another time during the operation of the furnace.

Keywords: ore-thermal furnace, ferroalloys, charge, fusion, melting temperature, elemental volume.

Качан Юрій Григорович - д.т.н., професор кафедри електропостачання промислових підприємств, Національний університет «Запорізька політехніка».

Міщенко Владислав Юрійович - асистент кафедри електропостачання промислових підприємств, Національний університет «Запорізька політехніка».

Kachan Yuriy - doctor of technical sciences, professor of the department of power supply of industrial enterprises, National university "Zaporizhzhya Polytechnic".

Mishchenko Vladyslav - assistant lecturer of the department of power supply of industrial enterprises, National university "Zaporizhzhya Polytechnic". 